\title{
Crystal structure and electrochemical properties of phosphosulphate $\mathrm{NaFe}_{2} \mathrm{PO}_{4}\left(\mathrm{SO}_{4}\right)_{2}$
}

\author{
Alexander A. Shindrov, Artem A. Kabanov, and Nina V. Kosova ${ }^{-}$ \\ Institute of Solid State Chemistry and Mechanochemistry, Siberian Branch of the Russian Academy \\ of Sciences, 18 Kutateladze, 630128 Novosibirsk, Russia
}

\begin{abstract}
NASICON-type $\mathrm{NaFe}_{2}\left(\mathrm{PO}_{4}\right)\left(\mathrm{SO}_{4}\right)_{2}$ (NFPS) electrode material is successfully synthesized via a rheological route. DSC/TG analysis shows that it is thermally stable up to $760{ }^{\circ} \mathrm{C}$. A carbon composite NFPS/C was obtained using ball milling. NFPS and NFPS/C were investigated as cathode and anode materials for sodium-ion batteries. Analysis of migration paths was performed by the Voronoi-Dirichlet partition technique to determine all possible $\mathrm{Na}^{+}$ion migration paths. The diffusion coefficient, estimated by GITT, is in the $10^{-12}-10^{-13} \mathrm{~cm}^{2} \cdot \mathrm{s}^{-1}$ range, which corresponds to the fast $\mathrm{Na}^{+}$ion migration in the structure. According to calculations, NFPS is a wide band gap material, which indicates its poor electrical conductivity.
\end{abstract}

\section{Introduction}

The study of chemical processes that convert the energy of a chemical redox reaction into electrical energy led to the creation of the first power sources in the XIX century and the award of the Nobel Prize for the development of high-performance lithium-ion batteries (LIBs) in the XXI century [1]. LIBs, which have been used with great success in smallscale portable devices, are now being considered as candidates for large-scale applications including electric vehicles and grid storage systems [2-5]. The growing applications of LIBs led to post lithium-battery era, where sodium-ion batteries (SIBs) [6] are a suitable alternative for partial or even full substitutions of LIBs due to lower costs and safety concerns.

However, SIBs has some disadvantages, such as a higher redox potential of $\mathrm{Na}^{+} / \mathrm{Na}^{0}(-$ $2.71 \mathrm{~V})$ compared to $\mathrm{Li}^{+} / \mathrm{Li}^{0}(-3.04 \mathrm{~V})$, a higher atomic mass $(23 \mathrm{~g} / \mathrm{mol} \mathrm{Na}$ vs. $7 \mathrm{~g} / \mathrm{mol} \mathrm{Li})$, and a larger ionic radius (1.02 $\AA$ for Na vs. $0.76 \AA$ for $\mathrm{Li})$, which, in turn, leads to the lower electrochemical properties. Despite the fact that SIBs are inferior in electrochemical characteristics of LIBs, the interest in their study does not become less. Currently, among the sodium-containing cathode materials, mixed-polyanion cathode materials attract special attention. The combination of polyanions in the structure makes it possible to tune the redox potential $\mathrm{M}^{(\mathrm{n}+)} / \mathrm{M}^{(\mathrm{n}+1)+}$ and, therefore, the energy density. Hexagonal NASICON-type $\mathrm{NaFe}_{2} \mathrm{PO}_{4}\left(\mathrm{SO}_{4}\right)_{2}$ is one of the most promising materials; its framework structure supports fast $\mathrm{Na}^{+}$conductivity with a possible participation of two $\mathrm{Na}$ ions per formula unit.

—Corresponding author: kosova@solid.nsc.ru 
Shiva et al. [7] synthesized $\mathrm{NaFe}_{2} \mathrm{PO}_{4}\left(\mathrm{SO}_{4}\right)_{2}$ and investigated its electrochemical properties in a $\mathrm{Na}$ cell. The synthesized sample was obtained with large amount of impurities and a surprising electrochemical behaviour such as capacity increase from 80 $\mathrm{mA} \cdot \mathrm{h} \cdot \mathrm{g}^{-1}$ to $100 \mathrm{~mA} \cdot \mathrm{h} \cdot \mathrm{g}^{-1}$ with cycling, which could not be interpreted by the authors. Yahia et al. [8] synthesized a pure $\mathrm{NaFe}_{2} \mathrm{PO}_{4}\left(\mathrm{SO}_{4}\right)_{2}$ and showed that the first discharge capacity is $89 \mathrm{~mA} \cdot \mathrm{h}^{-\mathrm{g}^{-1}}$ which is greater than in Ref. [7]. However, with subsequent cycling, the capacity is reduced to $56 \mathrm{~mA} \cdot \mathrm{h} \cdot \mathrm{g}^{-1}$. The reason of difference results $[7,8]$ may be related to different experimental conditions and requires more detailed study. In this paper, we investigate the crystal and electronic structure, thermal stability, transport and electrochemical properties of $\mathrm{NaFe}_{2} \mathrm{PO}_{4}\left(\mathrm{SO}_{4}\right)_{2}$.

\section{Experimental}

\subsection{Material synthesis}

$\mathrm{NaFe}_{2} \mathrm{PO}_{4}\left(\mathrm{SO}_{4}\right)_{2}$ (hereinafter NFPS) was prepared by the rheological synthesis. $5.4 \mathrm{~g}$ of

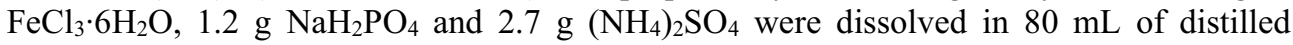
water and heated at $80{ }^{\circ} \mathrm{C}$ until evaporation of the liquid. The yellow amorphous product was heated at a temperature of $475^{\circ} \mathrm{C}$ in an air atmosphere for 12 hours. A greenish-yellow crystalline product NFPS was obtained as a result.

To prepare the carbon composite NFPS/C, NFPS was ball milled with $20 \%$ of carbon (Super P, Timcal Co.) using a SPEX 8000 mill with $0.6 \mathrm{~cm}$ diameter stainless steel balls for $15 \mathrm{~min}$. The ball-to-powder ratio was 20:1.

\subsection{Material characterization}

X-Ray powder diffraction (XRD) was performed using a Bruker D8 Advance diffractometer, $\mathrm{CuK} \alpha$ irradiation $(\lambda=1.54181 \AA$ A $)$. The XRD patterns were collected within the range of $2 \Theta=10-70$ with a step of $0.02 \mathrm{~s}^{-1}$ and an uptake time of $0.3 \mathrm{~s}$. Structural refinement of the lattice parameters was carried out by the Rietveld method using the GSAS software package [9]. Particle size and morphology were investigated by scanning electron microscopy (SEM) using a Hitachi S-3400 N scanning electron microscope. Thermal analysis (DSC/TG) was performed using a STA 449 F/1/1 JUPITER thermoanalyzer combined with a QMS403 CF AEOLOS mass-spectrometer. The infrared spectra were obtained with an "Infralum-801" FTIR spectrometer (Russia) within the 500$4000 \mathrm{~cm}^{-1}$ range (pellets with $\mathrm{KBr}$ ). The Mössbauer spectra were recorded using an NZ-640 spectroscope (Hungary) with a ${ }^{57} \mathrm{Co} \gamma$-ray source at room temperature.

For the electrochemical testing, the composite cathode was fabricated by mixing the active material, conductive carbon and PVDF/NMP binder in the ratio of 70:25:5 wt $\%$. The mixed slurry was then pasted on the aluminium (for cathode) or copper (for anode) foil using doctor blade, dried in vacuum at $90{ }^{\circ} \mathrm{C}$, and then cut into discs to obtain working electrodes. The loading density of the electrode mass was $\sim 2.0-2.5 \mathrm{mg} \cdot \mathrm{cm}^{-2}$, and the electrode diameter of $10 \mathrm{~mm}$ was used throughout. The Swagelok-type cells were assembled in an argon-filled glove box with $\mathrm{Na}$ as an anode, $1 \mathrm{M} \mathrm{NaPF}_{6}$ (Sigma Aldrich, 99\%) solution in a mixture of ethylene carbonate (Alfa Aesar, 99\%) and propylene carbonate (Sigma Aldrich, 99.7\%) 1:1 by weight as an electrolyte, and a glass fibre filter (Whatman, Grade GF/C) as a separator. Cycling was performed by means of Biologic BCS 805 using a galvanostatic mode at $\mathrm{C} / 20$ charge/discharge rate within the $2.0-4.4 \mathrm{~V}$ voltage range vs. $\mathrm{Na}^{+} / \mathrm{Na}^{0}$. The galvanostatic intermittent titration technique (GITT) measurements 
were carried out at $\mathrm{C} / 20$ rate $\left(\mathrm{I}_{0}=6.35 \mathrm{~mA} \cdot \mathrm{g}^{-1}\right)$ by applying a galvanostatic step for an interval of $20 \mathrm{~min}$ and a relaxation time for $40 \mathrm{~min}$.

\subsection{Computational methods}

Modeling of the migration pathways for $\mathrm{Na}^{+}$ions in NFPS was performed using the Voronoi-Dirichlet partition technique implemented in the ToposPro package [10]. The technique is based on the analysis of free space formed by the elementary voids and channels that might be accessible for migration of the mobile ions in a certain crystal structure. The accessibility of voids and channels for ion migration is determined by numerical criteria such as radii of an elementary void $R_{s d}$ and an elementary channel $R_{a d}$ [11]. The radius of the void is equal to the radius of a sphere with the volume of a Voronoi polyhedron; it corresponds to the radius of an atom that can be placed into this void taking into account the influence of the crystal field. The radius of the elementary channel corresponds to the minimum distance from the edge of the Voronoi polyhedron to the nearest atom. In the present work, the following criteria were used: $R_{a d} \geq 2.0 \AA$ and $R_{s d}=$ $1.54 \AA .-$

DFT calculations were performed using the Vienna Ab initio Simulation Package (VASP) [12] with the generalized gradient approximation $(\mathrm{GGA}+\mathrm{U})$ and exchangecorrelation functional in the Perdew-Burke-Ernzerhof (PBE) form [13]. We used a rotationally invariant approach proposed by Dudarev et al [14]. The U parameter for Fe metal was set to be $4.0 \mathrm{eV}$. For the geometry optimization, the convergence thresholds for the total energy and the ionic force components were chosen to be $10^{-6} \mathrm{eV}$ and $10^{-5} \mathrm{eV} / \AA$, respectively. The Brillouin zone was sampled with a $5 \times 5 \times 2$ Monkhorst-Pack k-points mesh, and the energy cut-off was set to $600 \mathrm{eV}$.

\section{Result and discussion}

\subsection{Crystal structure and morphology}

Fig. 1 shows XRD patterns of the NFPS and NFPS/C samples. The crystal structure was refined using the $\mathrm{NaTi}_{2}\left(\mathrm{PO}_{4}\right)_{3}$ structure as an initial structural model [15]. All peaks can be indexed in the trigonal structure with the $R-3 c$ space group.

The NASICON-type structure of NFPS can be described as a skeleton $\left[\mathrm{Fe}_{2} \mathrm{X}_{3} \mathrm{O}_{12}\right.$ ], built of $\mathrm{FeO}_{6}$ octahedra and $\mathrm{XO}_{4}$ tetrahedra $(\mathrm{X}=\mathrm{S}, \mathrm{P})$, which forms $3 \mathrm{D}$ interconnected channels with two types of interstitial positions, where sodium and vacancies are distributed. The $\mathrm{S}$ and $\mathrm{P}$ atoms are located in the same crystallographic position, and the occupancy of $2 / 3$ (S) and $1 / 3(\mathrm{P})$. According to XRD, ball milling with carbon does not lead to a significant disordering or decomposition of the structure.

SEM study shows that the morphology of the ball-milled NFPS/C samples is different from the morphology of NFPS. Small cubic crystals up to 5-7 $\mu \mathrm{m}$ in size are observed for the NFPS sample (Fig. 1c). The ball milling with carbon leads to a change in the shape of the particles and the formation of agglomerates up to $10-50 \mu \mathrm{m}$ in size (Fig. 1d). 

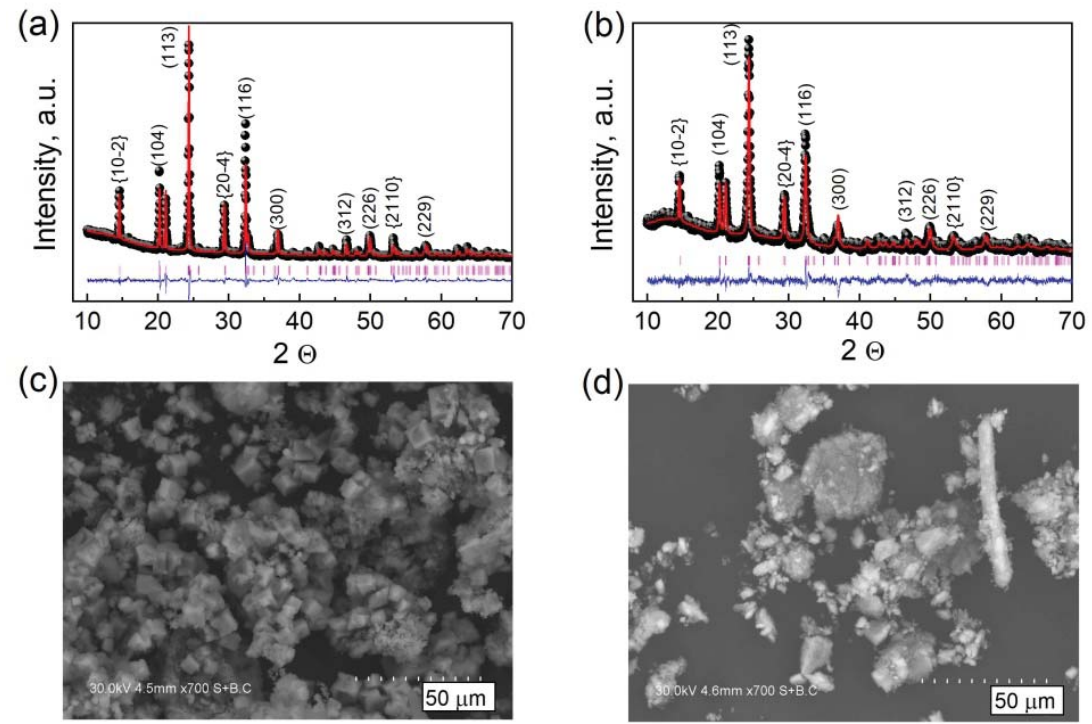

Fig. 1. XRD patterns (a, b) and SEM images (c, d) of the NFPS (a, c) and NFPS/C (b, d) samples.

\subsection{Thermal stability}

Thermal stability of NFPS was further studied by DSC/TG analysis. Fig. 2 shows the thermogravimetric (TG) and differential scanning calorimetric (DSC) curves and gas product evolution during heating of the NFPS sample. According to this data, NFPS is thermally stable up to a temperature of $760{ }^{\circ} \mathrm{C}$. The decomposition of the sample at higher temperatures is accompanied by a mass loss of $35 \%$ due to release of gases, such as $\mathrm{SO}_{2}$ and $\mathrm{O}_{2}$, which are formed by the following reaction:

$$
3 \mathrm{NaFe}_{2} \mathrm{PO}_{4}\left(\mathrm{SO}_{4}\right)_{2} \rightarrow 2 \mathrm{FePO}_{4}+2 \mathrm{Fe}_{2} \mathrm{O}_{3}+\mathrm{Na}_{3} \mathrm{PO}_{4}+6 \mathrm{SO}_{2} \uparrow+3 \mathrm{O}_{2} \uparrow
$$
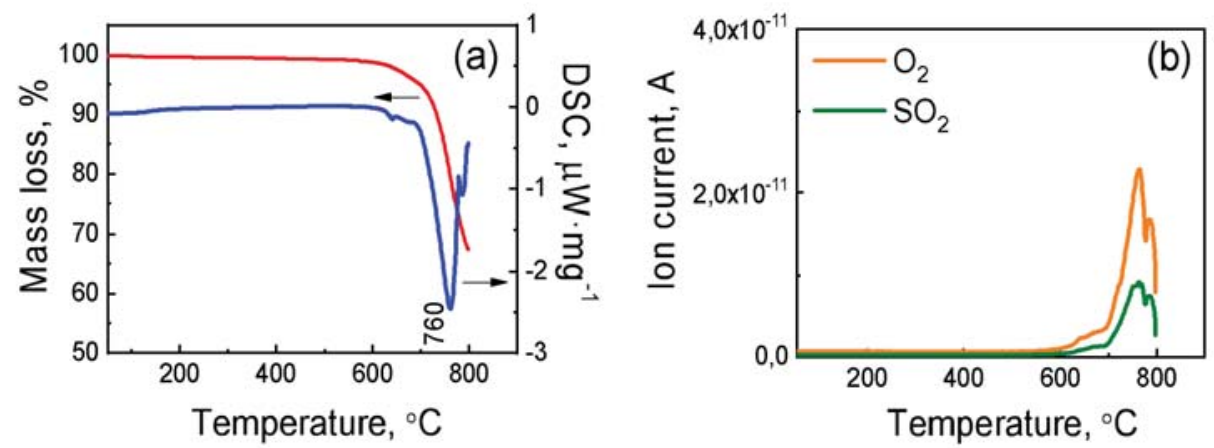

Fig. 2. DSC/TG curves (a) and gas products evolution (b) for NFPS.

\subsection{Local structure}

The local structure of the as-prepared NFPS sample was investigated by FTIR and Mössbauer spectroscopy. The FTIR spectrum shows the intramolecular vibrations of the 
$\mathrm{PO}_{4}{ }^{3-}$ and $\mathrm{SO}_{4}{ }^{2-}$ groups (Fig. 3). The stretching modes of $\mathrm{PO}_{4}{ }^{3-}$ and $\mathrm{SO}_{4}{ }^{2-}$ are within the $900-1200 \mathrm{~cm}^{-1}$ range, while the bending vibrations are within the $500-800 \mathrm{~cm}^{-1}$ range. The band at $1603 \mathrm{~cm}^{-1}$ refers to the $\mathrm{H}_{2} \mathrm{O}$ bending vibrations. The obtained FTIR spectrum confirms the presence of both $\mathrm{PO}_{4}{ }^{3-}$ and $\mathrm{SO}_{4}{ }^{2-}$ groups in the structure of NFPS.

The electronic state of the iron ions in NFPS was probed by the Mössbauer spectroscopy. The ${ }^{57} \mathrm{Fe}$ Mössbauer spectrum registered at room temperature is well fitted by the symmetric doublet assigned to the octahedral $\mathrm{Fe}^{3+}$ ions in its structure. The $I S$ and $Q S$ values are equal to $0.47 \mathrm{~mm} \cdot \mathrm{s}^{-1}$ and $0.78 \mathrm{~mm} \cdot \mathrm{s}^{-1}$, respectively. It should be noted that the spectrum shows an additional doublet associated with $\mathrm{Fe}^{2+}$ ions in the octahedral environment $\left(I S=1.29 \mathrm{~mm} \cdot \mathrm{s}^{-1}, Q S=2.43 \mathrm{~mm} \cdot \mathrm{s}^{-1}\right)$, but the $\mathrm{Fe}^{2+}$ content does not exceed $3 \%$. The data of FTIR and Mössbauer spectra of the NFPS/C composite are similar.
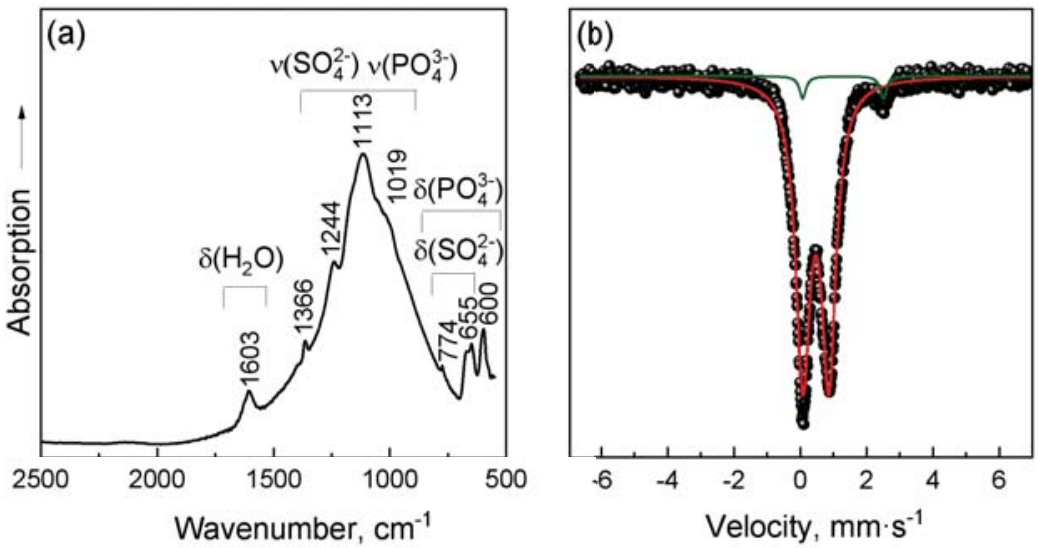

Fig. 3. FTIR (a) and ${ }^{57} \mathrm{Fe}$ Mössbauer (b) spectra of NFPS.

\subsection{Electrochemical properties}

The electrochemical properties of pristine NFPS and composite NFPS/C were investigated in a galvanostatic mode within the 2.0-4.4 V voltage range vs. $\mathrm{Na}^{+} / \mathrm{Na}^{0}$ at $\mathrm{C} / 20$ charge/discharge rate (Fig. 4). When using as cathode materials, the discharge capacity of NFPS and NFPS/C is $70 \mathrm{~mA} \cdot \mathrm{h} \cdot \mathrm{g}^{-1}$ and $56 \mathrm{~mA} \cdot \mathrm{h} \cdot \mathrm{g}^{-1}$, respectively, which is $55 \%$ and $43 \%$ of the theoretical capacity $\left(127 \mathrm{~mA} \cdot \mathrm{h}^{-1} \mathrm{~g}^{-1}\right.$ per $2 \mathrm{Na}$ ) (Figs. $\left.4 \mathrm{a}, \mathrm{c}\right)$. The $\mathrm{dQ} / \mathrm{dV}$ curves show the presence of two redox peaks at $2.9 \mathrm{~V}$ and $3.3 \mathrm{~V}$, corresponding to reduction of $\mathrm{Fe}^{3+} / \mathrm{Fe}^{2+}$ and oxidation of $\mathrm{Fe}^{2+} / \mathrm{Fe}^{3+}$ iron ions (Figs. 4b,d). The operating voltage is $3.1 \mathrm{~V}$, which is quite a high value among Na-based cathode materials.

With further cycling, the capacity value is stabilized. The reversible discharge capacity for NFPS and NFPS/C after the $20^{\text {th }}$ cycle is $46 \mathrm{~mA} \cdot \mathrm{h} \cdot \mathrm{g}^{-1}$ and $48 \mathrm{~mA} \cdot \mathrm{h} \cdot \mathrm{g}^{-1}$, respectively (Fig. $5)$. However, for NFPS/C there is an increase in polarization, probably, due to formation of agglomerates during the ball milling, which reduce the contacts between the particles and, therefore, make charge transfer (ions/electrons) more difficult. In addition, the occurrence of structural disordering or the formation of anti-site defects is possible. Despite the positive effect of ball milling with carbon on the electrochemical characteristics of other mixed-polyanion materials, e.g., $\mathrm{Na}_{3} \mathrm{FePO}_{4} \mathrm{CO}_{3}$ [16] and $\mathrm{NaFe}_{3}\left(\mathrm{SO}_{4}\right)_{2}(\mathrm{OH})_{6}[17,18]$, it is not the case for NFPS. 

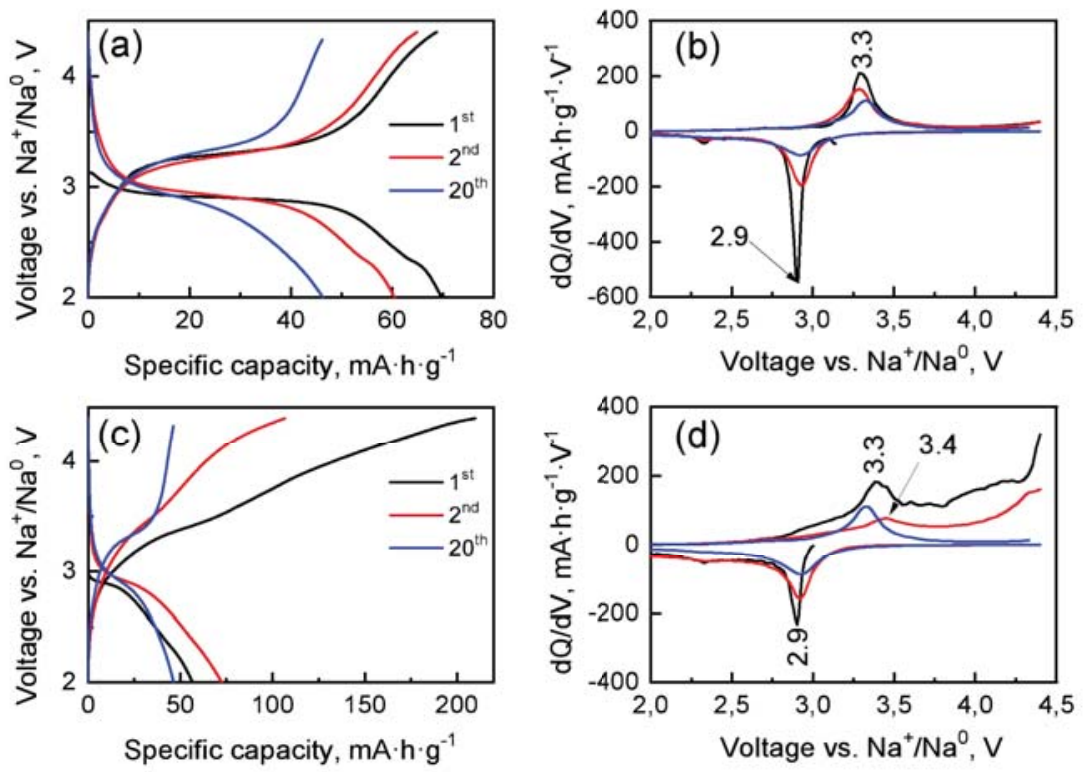

Fig. 4. Charge/discharge profiles $(a, c)$ and dQ/dV vs. voltage plots $(b, d)$ of NFPS and NFPS/C in the 2.0-4.4 $\mathrm{V}$ range at $\mathrm{C} / 20$ cycling rate.

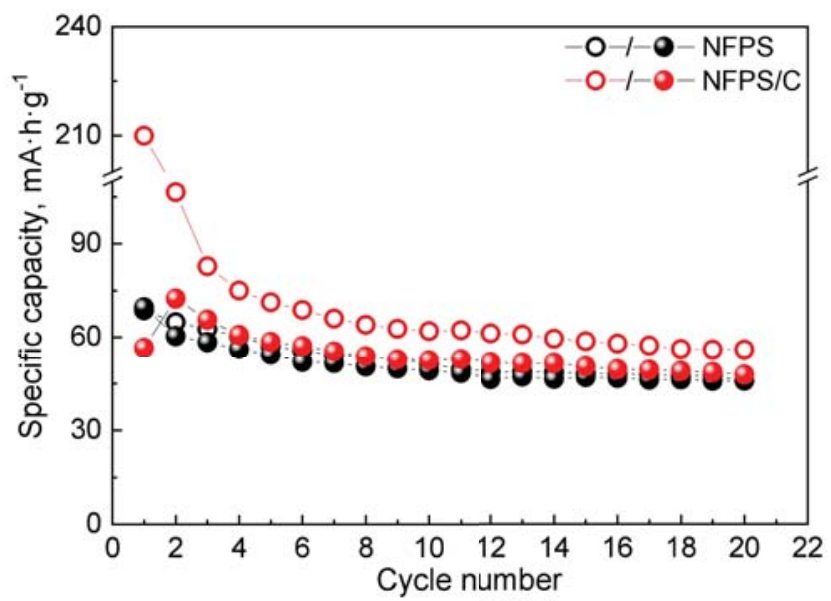

Fig. 5. Charge/discharge capacity vs. cycle number $(\mathrm{C} / 20)$.

NFPS was also investigated as anode material in the range of 0.1-2.0 $\mathrm{V}$ using $1 \mathrm{M}$ $\mathrm{NaPF}_{6}$ in $\mathrm{EC}: \mathrm{PC}(1: 1 \mathrm{vol} . \%)+\mathrm{VC}(5 \mathrm{wt} . \%)$ as an electrolyte at $\mathrm{C} / 20$ cycling rate (Fig. $\left.6 \mathrm{a}\right)$. The initial discharge capacity is $810 \mathrm{~mA} \cdot \mathrm{h} \cdot \mathrm{g}^{-1}$ that exceeds the theoretical value $(508$ $\left.\mathrm{mA} \cdot \mathrm{h} \cdot \mathrm{g}^{-1}\right)$. Note that this process is irreversible due to changes in the structure of NFPS and the occurrence of side reactions owing to interacting with the electrolyte, which leads to the formation of the solid electrolyte interface (SEI) (Fig. 6b). The charge capacity of the first cycle is much low, $177 \mathrm{~mA} \cdot \mathrm{h} \cdot \mathrm{g}^{-1}$. With subsequent cycling, the capacity gradually decreases. After one hundred cycles, it is equal to $51 \mathrm{~mA} \cdot \mathrm{h} \cdot \mathrm{g}^{-1}$ (Fig. 6b). 

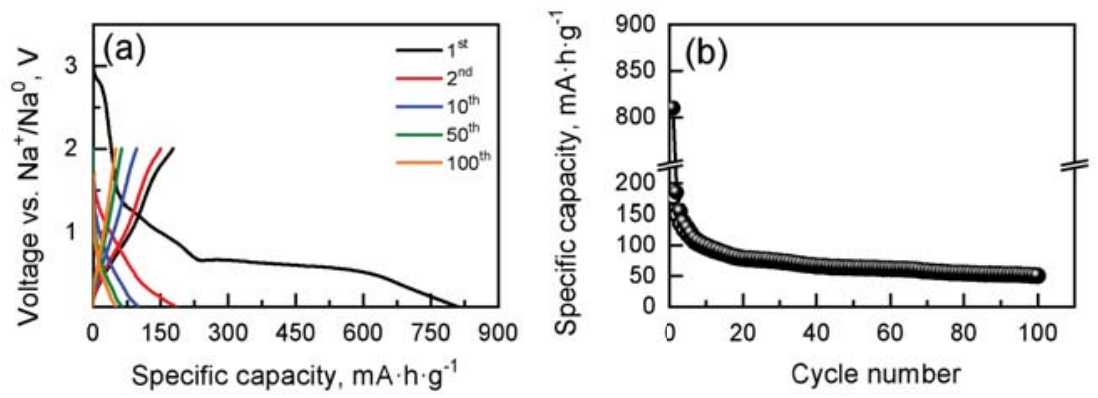

Fig. 6. Charge/discharge profiles in the $0.1-2.0 \mathrm{~V}$ range (C/20) (a), charge/discharge capacity vs. cycle number (b).

To find out how the structure changes during the reversible $\mathrm{Na}^{+}$intercalation, a series of XRD patterns were collected at various stages of cycling (Fig. 7). Upon the discharge process up to $1.3 \mathrm{~V}$, the structure does not change, but the reflections shift towards smaller angles, which can be due to the intercalation of additional $\mathrm{Na}^{+}$into the NFPS structure. The gradual disappearance of the peaks of the main phase occurs at $0.6 \mathrm{~V}$. The main phase completely disappears at $0.3 \mathrm{~V}$, and the new $\mathrm{Na}_{2} \mathrm{SO}_{4}$ phase is formed (PDF 1-990). The decomposition reaction can be represented by the following equations:

$$
\begin{gathered}
\mathrm{NaFe}_{2} \mathrm{PO}_{4}\left(\mathrm{SO}_{4}\right)_{2}+x \mathrm{Na}^{+}+x \mathrm{e}^{-} \rightarrow \mathrm{Na}_{1+x} \mathrm{Fe}_{2} \mathrm{PO}_{4}\left(\mathrm{SO}_{4}\right)_{2}(0<x<2) \\
\mathrm{Na}_{1+x} \mathrm{Fe}_{2} \mathrm{PO}_{4}\left(\mathrm{SO}_{4}\right)_{2}+(6-x) \mathrm{Na}^{+}+(6-x) \mathrm{e}^{-} \rightarrow 2 \mathrm{Fe}+\mathrm{Na}_{3} \mathrm{PO}_{4}+2 \mathrm{Na}_{2} \mathrm{SO}_{4}
\end{gathered}
$$

Equation (2) shows the intercalation of the additional $\mathrm{Na}^{+}$ions into the NFPS structure with the participation of the $\mathrm{Fe}^{3+} / \mathrm{Fe}^{2+}$ redox couple. A voltage of $1.3 \mathrm{~V}$ is the boundary above which the process of reversible intercalation occurs, while at lower voltage values (below $1.3 \mathrm{~V}$ ), the irreversible decomposition of the sample takes place. In the course of decomposition, the iron ions are reduced to the metallic state $\mathrm{Fe}^{2+} \rightarrow \mathrm{Fe}^{0}$. According to Eq. (3), in addition, the sodium salts $\mathrm{Na}_{2} \mathrm{SO}_{4}$ and $\mathrm{Na}_{3} \mathrm{PO}_{4}$ are formed. $\mathrm{Na}_{3} \mathrm{PO}_{4}$ and $\mathrm{Fe}$ are in amorphous state and do not appear on the XRD pattern. Thus, due to the decomposition of NFPS at low voltages, it cannot be considered as an anode material.

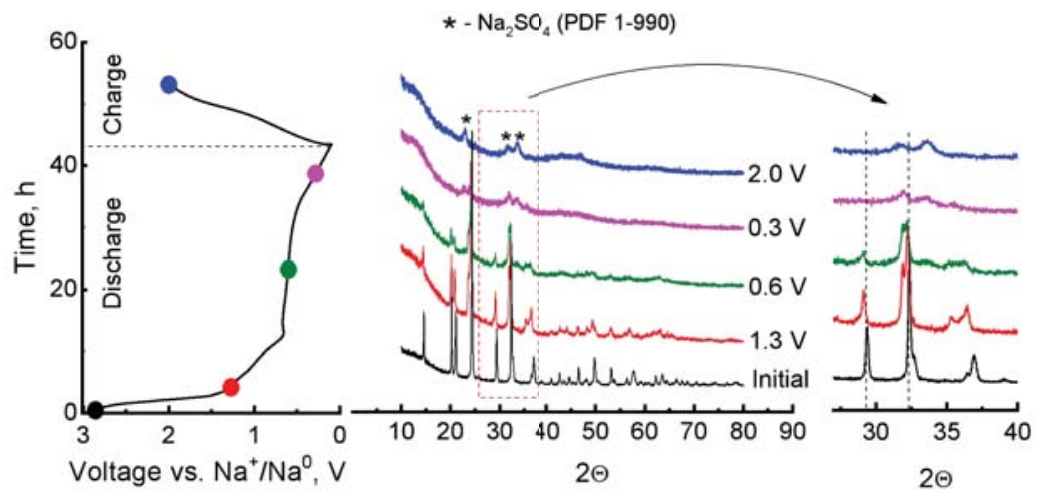

Fig. 7. Structural changes in NFPS during cycling. 


\subsection{Ion transport and electron structure of NFPS}

The diffusion paths for $\mathrm{Na}^{+}$ions in the NFPS structure were identified using the wellestablished geometrical approach based on the Voronoi- Dirichlet partition (VDP) of crystal space (Fig. 8a). To determine the significant elementary channels and voids, the following values of the radius of the elementary void $R_{s d}$ and the elementary channel $R_{\text {ad }}$ were selected as $\mathrm{R}_{\mathrm{sd}}=1.54 \AA$ and $\mathrm{R}_{\mathrm{ad}} \geq 2.0 \AA$. The selected values are standard for sodium-ion conductors [19]. All the elementary channels are significant, i.e. the migration of $\mathrm{Na}^{+}$ions in the structure of NFPS is possible without any increase in temperature and structural changes, as in the case of $\mathrm{NaFe}_{3}\left(\mathrm{SO}_{4}\right)_{2}(\mathrm{OH})_{6}$ [17]. The migration of sodium ions is possible along the [111] direction. This approach provides only a primary estimation of the diffusion system and is used to obtain preliminary data.

(a)

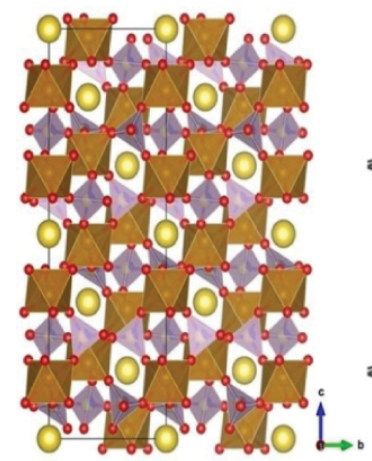

(b)

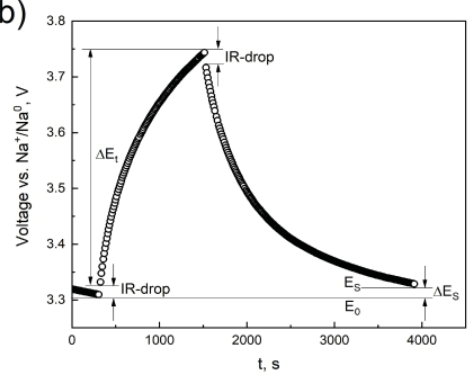

(d)

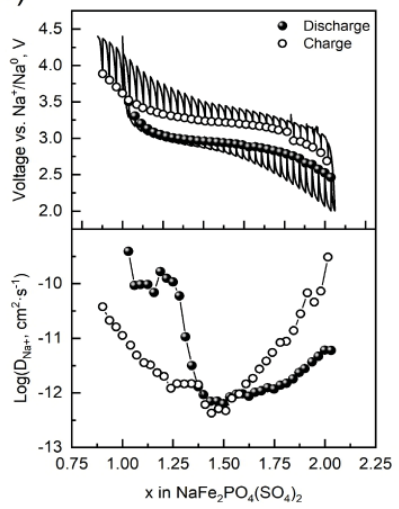

(c)

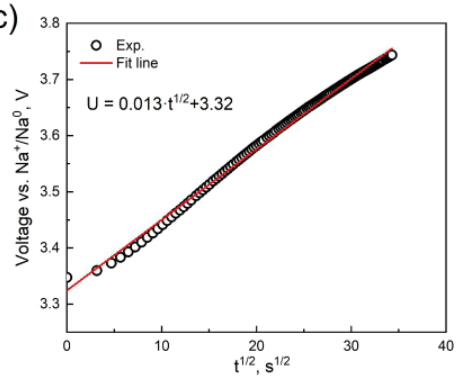

Fig. 8. (a) Migration maps of $\mathrm{Na}^{+}$ions, (b) voltage $V$ vs. time $t$ profile for a single GITT titration at the state of charge, (c) voltage $V$ vs. $t^{1 / 2}$ plot, (d) diffusion coefficient $D_{\mathrm{Na}+}$ as a function of inserted amount of $\mathrm{Na}^{+}$ions.

To estimate the diffusion coefficient of $\mathrm{Na}^{+}$ions during cycling, the galvanostatic intermittent titration technique (GITT) was used. Fig. 8d shows the dependence of the diffusion coefficient $D_{\mathrm{Na}}$ vs. the sodium ion content $x$ for NFPS. $\mathrm{D}_{\mathrm{Na}}$ was calculated using the following equation:

$$
D_{N a^{+}}=\frac{4}{\pi}\left(\frac{V_{M}}{S F}\right)^{2}\left(I_{0} \frac{\frac{\delta E_{s}}{\delta x}}{\frac{\delta E}{\delta t^{\frac{1}{2}}}}\right)^{2}, t \ll \tau
$$


where $V_{M}$ is the molar volume, $S$ is the real surface area of all particles in the electrode, $F$ is the Faraday's constant, $I_{0}$ is the current pulse, $\delta E_{\mathrm{s}} / \delta x$ is the slope of the equilibrium open circuit voltage $v s$. the alkaline ion content $x$ and $\delta E / \delta t^{1 / 2}$ is the slope of a voltage change $v s$. the square root of time. The applied current pulse and the resulting potential profile of NFPS for a single titration are shown in Fig. 8b. Various parameters, $\Delta \mathrm{E}_{\mathrm{t}}, \Delta \mathrm{E}_{\mathrm{S}}$, etc., are labelled schematically. Fig. 8c shows a rather good linear relationship of $E$ vs. $t^{1 / 2}$, which indicates that Eq. (4) is suitable for the calculation of $D_{\mathrm{Na}+}$. The average value of the diffusion coefficient of $\mathrm{D}_{\mathrm{Na}+}$ for NFPS upon discharge and charge is equal to $3.84 \cdot 10^{-11}$ and $3.80 \cdot 10^{-11} \mathrm{~cm}^{2} \cdot \mathrm{s}^{-1}$, respectively (Fig. $8 \mathrm{~b}$ ).

Despite fast $\mathrm{Na}^{+}$diffusion in the NFPS structure, the discharge capacity is far from the theoretical value. The reason, presumably, is in the low electronic conductivity of NFPS. Indeed, an increase in the discharge capacity of NFPS was achieved by adding a large amount of conductive soot $(50 \mathrm{wt} \%)$ to the cathode mass as described in refs. $[7,20]$. However, with long-term cycling, the capacity gradually decreases and is $55 \%$ of the original value after 100 cycles [20].

For a deeper understanding of the electronic structure of NFPS, the density of states (DOS) was calculated (Fig. 9). According to calculations, NFPS has a wide band gap, which indicates poor electrical conductivity of the material. Due to the low decomposition temperature of NFPS, the creation of the conductive carbon coating using high-temperature pyrolysis of organic compounds (above $650{ }^{\circ} \mathrm{C}$ ) is quite problematic. The use of mechanical activation to create a carbon composite is also not suitable, since it leads to structural disordering and worsening of electrochemical characteristics as a result. On the other hand, electronically conductive polymers can be used as an alternative way to create a carbon composite [21].

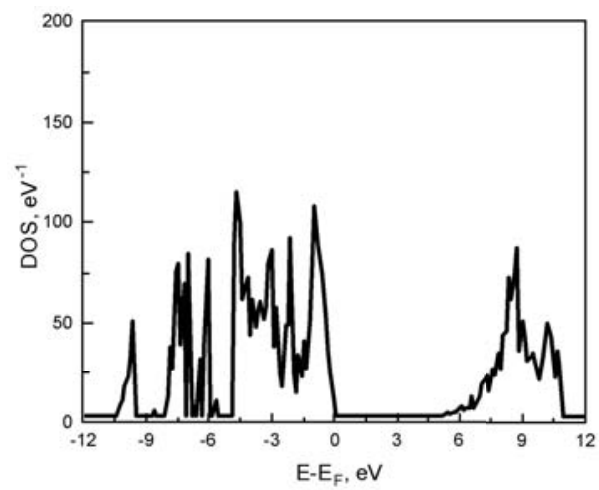

Fig. 9. Calculated density of states for NFPS.

\section{Conclusion}

Pure-phase NFPS was successfully synthesized for the first time via a rheological method. The discharge capacity of NFPS and its carbon composite NFPS/C is $70 \mathrm{~mA} \cdot \mathrm{h} \cdot \mathrm{g}^{-1}$ and 56 $\mathrm{mA} \cdot \mathrm{h} \cdot \mathrm{g}^{-1}$, which is $55 \%$ and $43 \%$ of the theoretical capacity in the $2.0-4.4 \mathrm{~V}$ voltage range. It is shown that ball milling leads to agglomeration of particles and, as a result, to deterioration of electrochemical characteristics. The structure of NFPS remains stable to 1.3 $\mathrm{V}$. Because of decomposition of NFPS at low voltages (below $1.3 \mathrm{~V}$ ), it cannot be considered as an anode material. Cycling to lower voltage leads to the irreversible decomposition of NFPS to form metallic iron Fe and sodium salts $\mathrm{Na}_{2} \mathrm{SO}_{4}$ and $\mathrm{Na}_{3} \mathrm{PO}_{4}$. The analysis of ion transport shows that $\mathrm{Na}^{+}$ion migration occurs in the [111] direction. 
According to GITT, the diffusion coefficient of $\mathrm{Na}^{+}$ions upon discharge and charge is $5.0 \cdot 10^{-13}$ and $4.8 \cdot 10^{-12} \mathrm{~cm}^{2} \cdot \mathrm{s}^{-1}$, respectively, which indicates the fast migration of $\mathrm{Na}^{+}$ions in the structure. Based on the DFT calculations, NFPS has a wide band gap, which indicates poor electronic conductivity of the material.

The study was supported by FWUS-2021-0006 and RFBR, grant \# 19-33-90203.

\section{References}

1. M.S. Whittingham, J. Power Sources 473, 8 (2020)

2. N. Nitta, F. Wu, J.T. Lee, G. Yushin, Mater. Today. 18, 252 (2015)

3. J.B. Goodenough, Y. Kim, Chem. Mater. 22, 587 (2010)

4. F. Schipper, E.M. Erickson, C. Erk, J.-Y. Shin, F.F. Chesneau, D. Aurbach, J. Electrochem. Soc. 164, A6220 (2017)

5. J.B. Goodenough, K.S. Park, J. Am. Chem. Soc. 135, 1167 (2013)

6. N. Yabuuchi, K. Kubota, M. Dahbi, S. Komaba, Chem. Rev. 114, 11636 (2014)

7. K. Shiva, P. Singh, W. Zhou, J.B. Goodenough, Energy Environ. Sci. 9, 3103 (2016)

8. H. Ben Yahia, R. Essehli, R. Amin, K. Boulahya, T. Okumura, I. Belharouak, J. Power Source 382, 144 (2018)

9. B.H. Toby, J. Appl. Crystallogr. 34, 210 (2001)

10. V.A. Blatov, A.P. Shevchenko, D.M. Proserpio, Cryst. Growth Des. 14, 3576 (2014)

11. V.A. Blatov, G.D. Ilyushin, O.A. Blatova, N.A. Anurova, A.K. Ivanov-Schits, L.N. Dem'yanets, Acta Crystallogr. Sect. B Struct. Sci. 62, 1010 (2006)

12. G. Kresse, J. Furthmüller, Phys. Rev. B. 54, 11169 (1996)

13. J.P. Perdew, K. Burke, M. Ernzerhof, Phys. Rev. Lett. 77, 3865 (1996)

14. S.L. Dudarev, G.A. Botton, S.Y. Savrasov, C.J. Humphreys, A.P. Sutton, Phys. Rev. B. 57, 1505 (1998)

15. G. Pang, C. Yuan, P. Nie, B. Ding, J. Zhu, X. Zhang, Nanoscale 6, 6328 (2014)

16. N. V. Kosova, A.A. Shindrov, A.B. Slobodyuk, D.G. Kellerman, Electrochim. Acta 302, 119 (2019)

17. N. V Kosova, A.A. Shindrov, A.A. Kabanov, Electrochim. Acta. 359, 136950 (2020)

18. N. V. Kosova, A.A. Shindrov, Mater. Today Proc. 25, 420 (2019)

19. F. Meutzner, W. Münchgesang, N.A. Kabanova, M. Zschornak, T. Leisegang, V.A. Blatov, D.C. Meyer, Chem. - A Eur. J. 21, 16601 (2015)

20. S.F. Li, Z.Y. Gu, J.Z. Guo, X.K. Hou, X. Yang, B. Zhao, X.L. Wu, J. Mater. Sci. Technol. 78, 176 (2021)

21. V.A. Nguyen, C. Kuss, J. Electrochem. Soc. 167, 065501 (2020) 